

RESEARCH ARTICLE

\title{
HISTOLOGICAL EFFECTS OF BISPHENOL- A ON REPRODUCTIVE ORGANS OF FEMALE WISTAR RATS.
}

Noopur Dhagga, M.Sc., Priya Gupta, M. Sc and "Srivastava Seema Ph.D, M.Sc. Reproductive Physiology Laboratory, Department of Zoology, University of Rajasthan, Jaipur-302004 (India).

\section{Manuscript Info}

Manuscript History

Received: 02 September 2017

Final Accepted: 04 October 2017

Published: November 2017

Key words:-

Bisphenol-A (BPA), hormone, ovary, uterus, body weight.

\section{Abstract}

BisphenolA (BPA) is one of the most widespread endocrine disrupting chemicals used in the manufacturing of plastics. Many evidences report many harmful effects on health. The aim of the present work was to study the effects of bisphenol-A on reproductive organs (ovary and uterus) and hormone level (estrogen and progesterone) and body weight of female wistar albino rats. Adult females were orally administered the dose of BPA $(5,50,300,600$ and $800 \mathrm{mg} / \mathrm{kg}$ bw/week) for 3 months. Animals were sacrificed; body weight measured and the level of estrogen and progesterone with respect to ovary and uterus were examined. At the doses of groups $(50,300,600 \& 800 \mathrm{mg}$ BPA), significant changes were noticed in body weight but at the dose of $5 \mathrm{mg}$ of BPA, no significant decline was observed. Significant changes were observed in hormone level, ovary and uterus of non pregnant females. In cesarean and post term phases, the level of hormone non significantly decreased and the changes in ovary and uterus were not noted. In conclusion, this study emphasized more on histology of reproductive organs and the adverse effects of BPA on females.

Copy Right, IJAR, 2017,. All rights reserved.

\section{Introduction:-}

Estrogenic endocrine disruptors (EEDs) are environmental compounds that are able to bind estrogen receptors (ERs) and evoke biological responses. Several authors exert a great effort to demonstrate the estrogenic activity of EED in vitro and in vivo. One of these EED is bisphenol-A (BPA) ${ }^{1}$. BPA is an organic compound with two phenol functional groups. Bisphenol-A is a widely used as industrial plasticizer with weak estrogenicity ${ }^{2}$. BPA can leach from plastic products ${ }^{3}$. The general human population can be exposed BPA mainly via ingestion, inhalation and skin contact $^{2-5,7-8}$. Heat and either acidic or basic conditions induce hydrolysis of the ester bond linking BPA monomers, leading to release of BPA into food and liquid and making human environmental exposure assured and ubiquitous ${ }^{4,6}$. In human the BPA is absorbed, rapidly metabolized in the liver, mainly BPA glucuronide ${ }^{9}$ with a biological half-life of approximately six hours ${ }^{10}$ and nearly complete elimination (excreted > 90\%) within $24 \mathrm{hr}^{10,11}$.

However, numerous studies demonstrate that BPA at too low concentrations activate nuclear ERs efficiently and also have cellular effects ${ }^{5,7}$. BPA reportedly have the potential to produce widespread adverse effects through their endocrine disrupting activity, such as carcinogenicity, immunotoxicity, neurotoxicity, developmental abnormalities, and so on $^{5,8}$. Many studies in animal models have reported decreased sperm motility, impaired spermatogenesis and decreased fertility in male reproductive system ${ }^{12,13}$. Toxicity of BPA in females acts adversely on reproductive system and subsequently on fertility. Therefore the objective of the current study was to evaluate the body weight 
and changes in serum hormonal level in relation with ovary and uterus histology. The oral route of exposure was selected for the study to simulate the most common route of exposure of humans to BPA.

\section{Materials and Methods:-}

Test material:-

Bisphenol A [2, 2-bis (4-hydroxyphenyl propane)] (purity 99.5\%, CAS no. 80-05-7) was purchased from Sigma Aldrich.

\section{Animals:-}

Adult female Wistar rats, 5-6 months old, weighing 180-220 grams, were used in investigation. The animals bred in our laboratory and maintained in the Departmental Experimental Facility with light and dark (12h:12h) schedule in individual cage. The temperature in animal house during study period was maintained at $23 \pm 2{ }^{\circ} \mathrm{C}$ and relative humidity was ranged between 32 and $70 \%$. Animals were fed with rat pellet diet (Ashirwad Industries Limited, Chandigarh) and free access to safe drinking water ad libitum in glass bottles. The animals were maintained under perfect veterinary supervision and accordance to the guidelines ${ }^{14}$.

\section{Experimental Design:-}

Experiment was carried out in accordance with the OECD guidelines for testing chemicals- acute oral toxicity- fixed dose procedure ${ }^{15}$. The maximum dose of BPA was selected after finding out the $\mathrm{LD}_{50}$ as $840 \mathrm{mg} / \mathrm{kg}$ body weight via intraperitoneal. Animals were allocated into six groups, containing ten animals each. Parallel control used for termination of each phase. During treatment all animals were allowed to mate and get pregnant depending on the possibilities of outcome, namely, non pregnancy, cesarean and full-term of pregnancy.

Group I: Control (vehicle treated)

Group II: Oral administration of $5 \mathrm{mg} \mathrm{BPA} / \mathrm{kg}$ bd. wt. /week

Group III: Oral administration of $50 \mathrm{mg}$ BPA/kg bd. wt. /week

Group IV: Oral administration of $300 \mathrm{mg} \mathrm{BPA} / \mathrm{kg}$ bd. wt. /week

Group V: Oral administration of $600 \mathrm{mg} \mathrm{BPA} / \mathrm{kg}$ bd. wt. /week

Group VI: Oral administration of $800 \mathrm{mg} \mathrm{BPA} / \mathrm{kg}$ bd. wt. /week

\section{Doses and Autopsy Schedule:-}

Doses to all females were given orally for 3 months of treatment. Pregnant females received dose for 0-19 days of gestation and necropsies were done on 20th day of gestation and after full term delivery. For non pregnant, scarification of females were done in diestrous phase only.

\section{Body Weight:-}

The body weight of all animals measured initially and final body weight obtained at the time of euthanization at the termination of schedule or fatality.

\section{Hormone Analysis:-}

Following sodiumpentobarbitalanaesthesia blood was collected by cardiac puncture and serum was separated. Following separation of serum, levels of progesterone and estrogen were measured by ELISA kit.

\section{Histopathology:-}

Reproductive organs (ovaries, uterus) fixed in 4\% paraformaldehyde, dehydrated in ethanol, cleared in Xylene and embedded in paraffin wax. Five micron thick section will be stained with haematoxylin and eosin for light microscopic observation.

\section{Statistical Analysis:-}

The mean values was compared using respective standard deviations followed by statistical comparison between control and test groups for evaluation of significant changes in values by Student's t-test and one way analysis of variance (ANOVA) test. $\mathrm{P}<0.05$ was considered as significant. 


\section{Results:-}

Body Weight:-

A significant decline in body weights was observed, following 50,300, 600 and $800 \mathrm{mg} / \mathrm{kg}$ bw/week of BPA in phase of non pregnant whereas cesarean $(5 \mathrm{mg} / \mathrm{kg}$ bw/week $)$ and post term $(5 \mathrm{mg} / \mathrm{kg} \mathrm{bw} /$ week $)$ phases had non significant body weight respectively (Figure 1A-1C) in comparison to control group females.

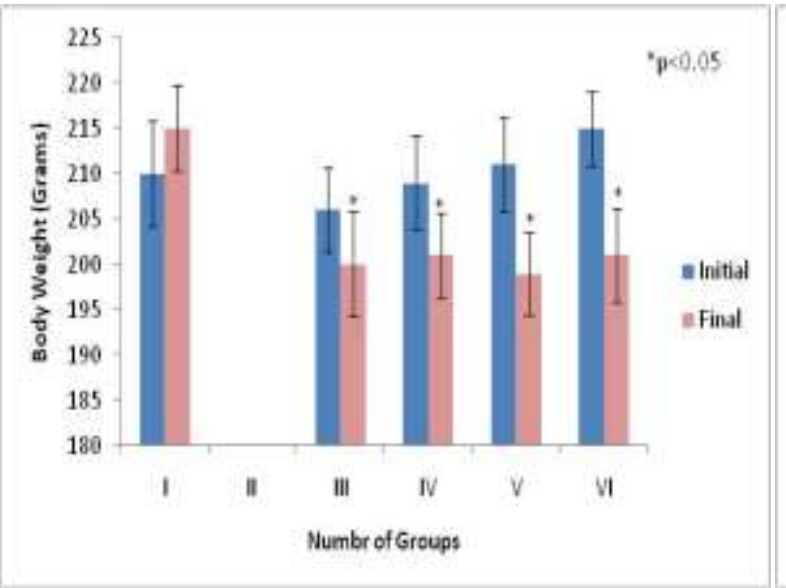

Figure 1A

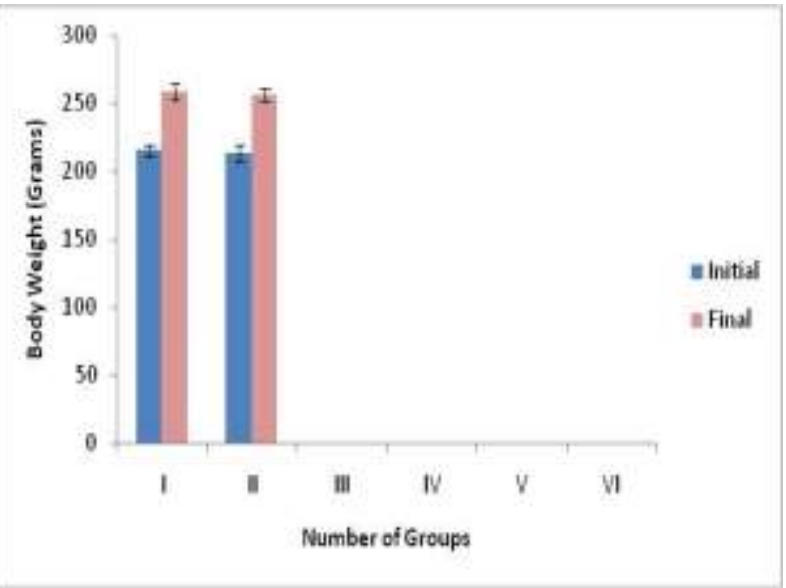

Figure 1B

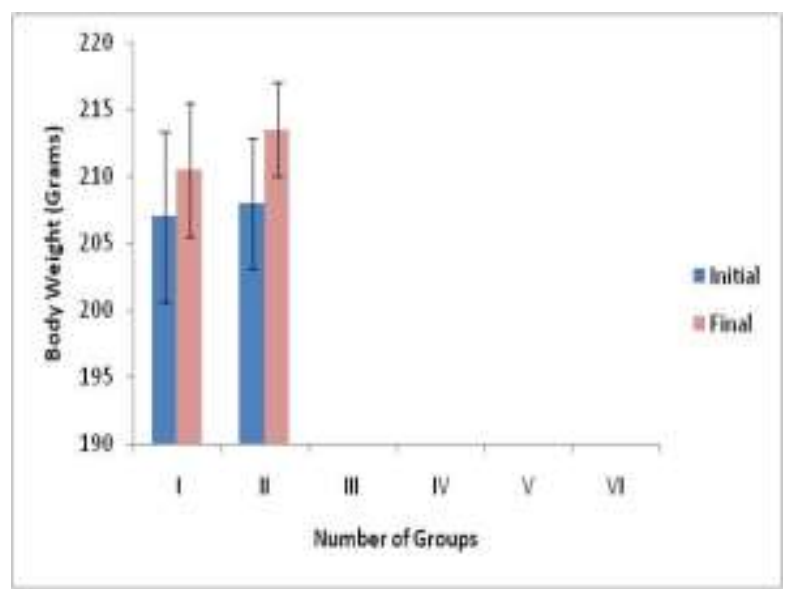

Figure 1C

Figure 1:- The graphical representation of initial and final body weight. A Non pregnant phase (tested using one way ANNOVA). B Cesarean phase (tested using Student's t test). C Post term phase (tested using Student's t test).

$*$ Significant at $\mathrm{p}<0.05$.

\section{Hormone level:-}

A significant decline in the hormone levels of BPA $(50,300,600$ and $800 \mathrm{mg} / \mathrm{kg}$ bw/week) treated female rats was observed. The serum estradiol and progesterone were decreased significantly in non pregnant phase of all groups (Table 1). In cesarean phase, non significantly decrease in estradiol and progesterone level were seen (Table 2) in comparison to control. In case of post term pregnancy phase, estradiol and progesterone were decreased non significantly with the BPA dose (Table 3).

Table 1:- Effect of BPA on circulatory hormones level following control and treated in non pregnant phase of Wistar rat

\begin{tabular}{|c|c|c|}
\hline Groups & Estradiol $(\mathrm{pg} / \mathrm{ml})$ & Progesterone $(\mathrm{ng} / \mathrm{ml})$ \\
\hline Group I & $6.2 \pm 0.15$ & $4.7 \pm 0.15$ \\
\hline Group II & - & - \\
\hline Group III & $4.68 \pm 0.14^{*}$ & $2.46 \pm 0.12^{*}$ \\
\hline
\end{tabular}




\begin{tabular}{|c|c|c|}
\hline Group IV & $2.1 \pm 0.08^{*}$ & $0.78 \pm 0.10^{*}$ \\
\hline Group V & $1.3 \pm 0.14^{*}$ & $0.22 \pm 0.10^{*}$ \\
\hline Group VI & $0.5 \pm 0.08^{*}$ & $0.07 \pm 0.008^{*}$ \\
\hline
\end{tabular}

Data are expressed as the mean \pm s.d. $(\mathrm{n}=10) \quad * \mathrm{p}<0.05$

Table 2:- Effect of BPA on circulatory hormones level following control and treated in cesarean phase of Wistar rats

\begin{tabular}{|c|c|c|}
\hline Groups & Estradiol (pg/ml) & Progesterone (ng/ml) \\
\hline Group I & $4.13 \pm 0.08$ & $6.2 \pm 0.15$ \\
\hline Group II & $4.02 \pm 0.10$ & $6.08 \pm 0.09$ \\
\hline Group III & - & - \\
\hline Group IV & - & - \\
\hline Group V & - & - \\
\hline Group VI & - & - \\
\hline
\end{tabular}

Data are expressed as the mean \pm s.d. $(n=10)$

Table 3:- Effect of BPA on circulatory hormones level following control and treated in post term phase of Wistar rats

\begin{tabular}{|c|c|c|}
\hline Groups & Estradiol $(\mathrm{pg} / \mathrm{ml})$ & Progesterone $(\mathrm{ng} / \mathrm{ml})$ \\
\hline Group I & $3.81 \pm 0.08$ & $1.49 \pm 0.09$ \\
\hline Group II & $3.73 \pm 0.06$ & $1.40 \pm 0.08$ \\
\hline Group III & - & - \\
\hline Group IV & - & - \\
\hline Group V & - & - \\
\hline Group VI & - & - \\
\hline
\end{tabular}

Data are expressed as the mean \pm s.d. $(n=10)$

\section{Histopathology of organs:-}

Ovary:-

The effects of BPA $(50,300,600$ and $800 \mathrm{mg} / \mathrm{kg}$ bw/week) impaired the ovarian developing follicles in non pregnant phase. (Figure 2A-E). In cesarean phase, there were naturally atretic phenomenon in primary developing follicles of BPA treated $(5 \mathrm{mg} / \mathrm{kg}$ bw/week) animals when compared with control group (Figure 3A-B). The developing follicles in post term phase were remain unchanged of BPA treated ( $5 \mathrm{mg} / \mathrm{kg}$ bw/week) animals to the control group (Figure 4A-B).

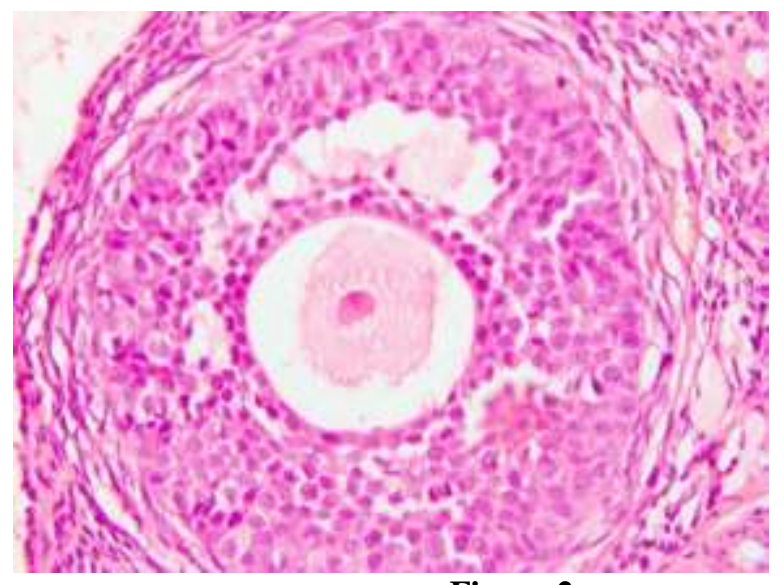

Figure 2a

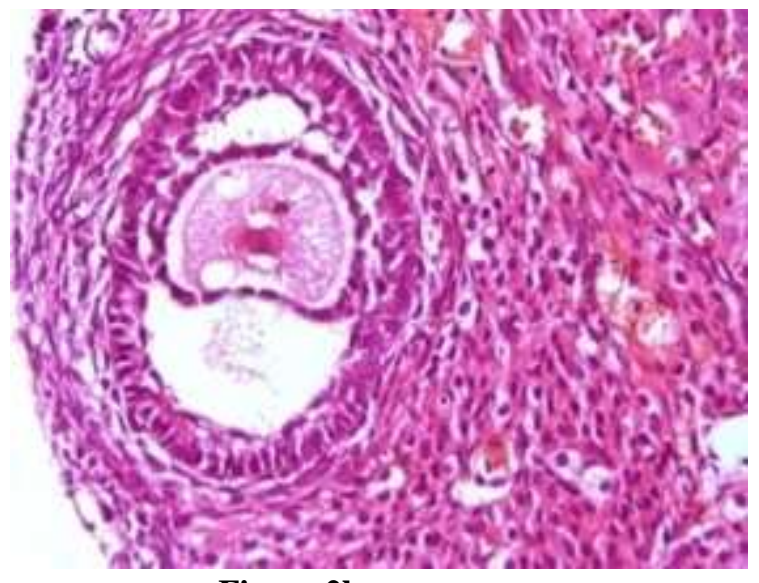

Figure 2b 

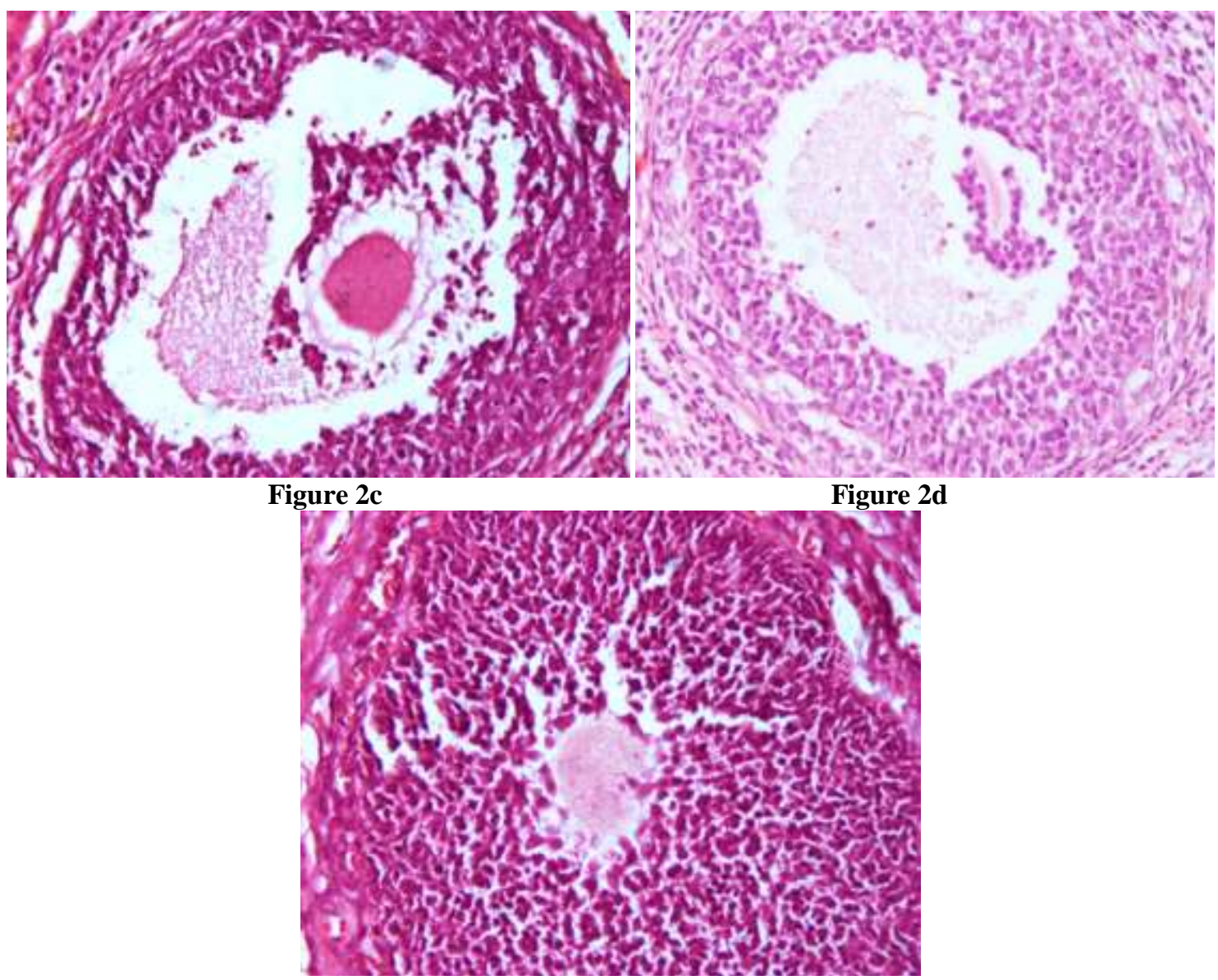

Figure 2e

Figure 2:-Histoarchitecture of ovary in non pregnant animals. A Histology of ovary in group I (control) animals showing normal atresia in developing follicles. B-E Histology of ovary of BPA treated groups III, IV, V and VI (50, 300,600 and $800 \mathrm{mg} / \mathrm{kg}$ bd.wt./week) animals showing huge atresia in developing follicles. (H\&E, X400).

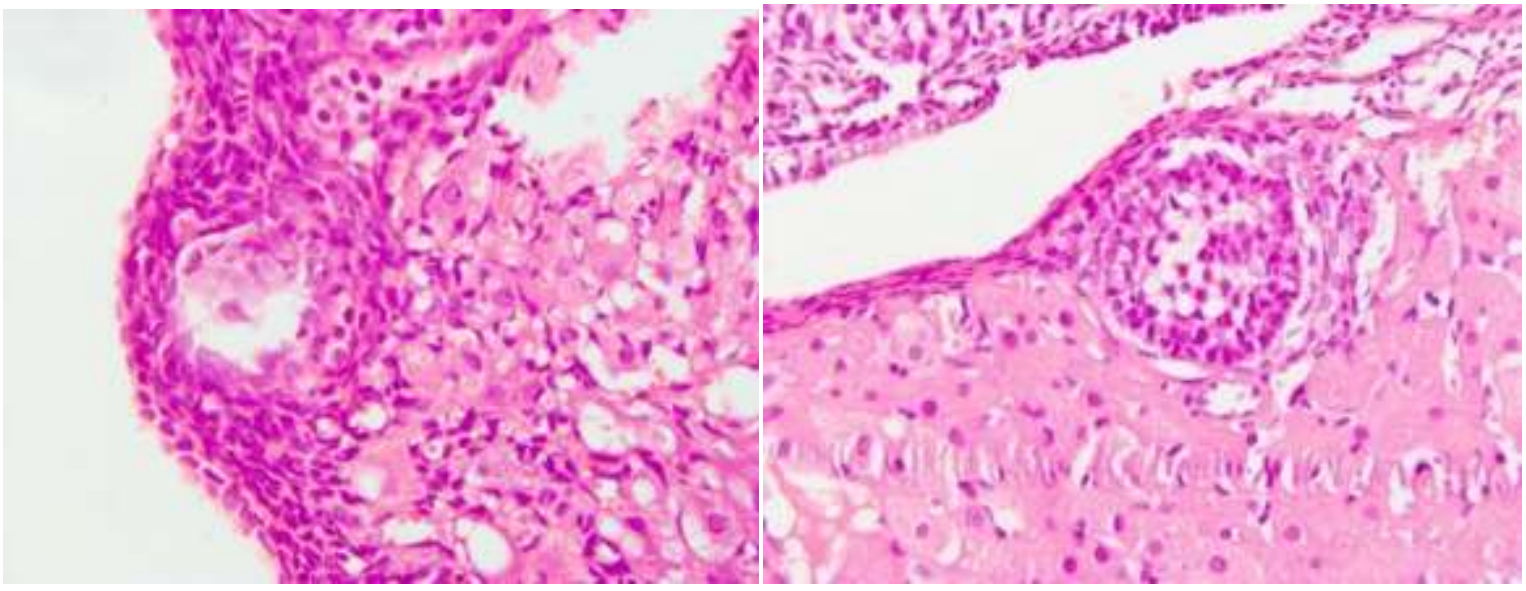

Figure 3a

Figure 3b

Figure 3:-Histoarchitecture of ovary in cesarean animals. A-B Histology of ovary in group I (control) and BPA treated group II ( $5 \mathrm{mg} / \mathrm{kg}$ bd.wt./week) animals showing normal atresia in developing primary follicles. (H\&E, $\mathrm{X} 400)$. 


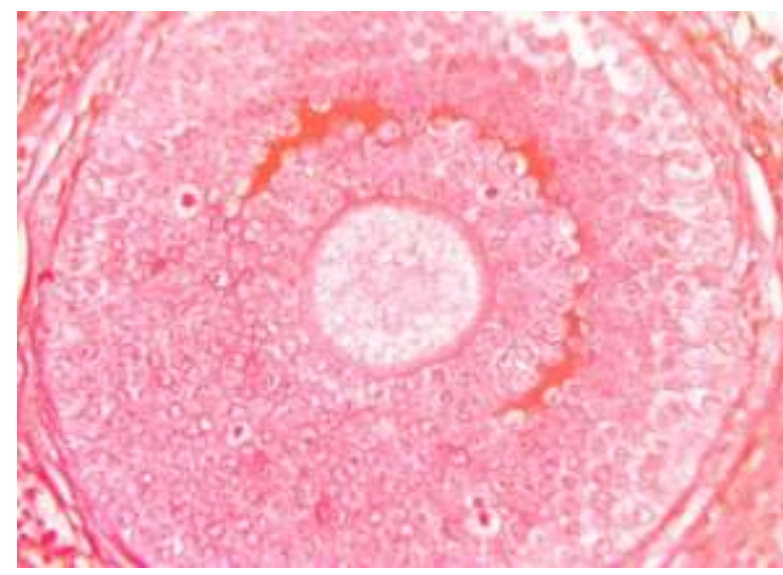

Figure 4a

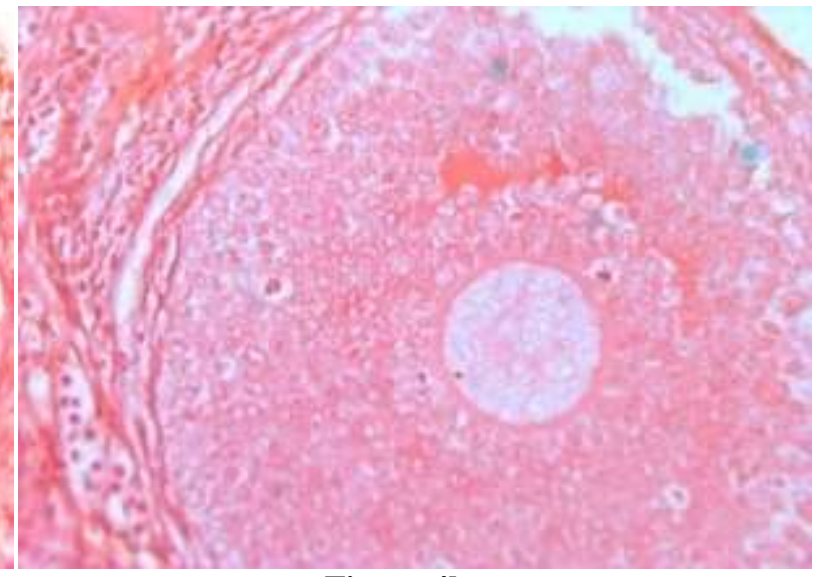

Figure 4b

Figure 4:-Histoarchitecture of ovary in post term animals. A-B Histology of ovary in group I (control) and BPA treated group II (5 mg/kg bd.wt./week) animals showing normal developing follicles. (H\&E, X400).

\section{Uterus:-}

The morphological changes in the luminal epithelial of uterus could be observed in non pregnant phase of BPA treated animals when compared with control group. The thickness of the total epithelium was significantly reduced after exposure of different doses of BPA $(50,300,600$ and $800 \mathrm{mg} / \mathrm{kg}$ bw/week) when compared with control group (Figure 5A-5E). In cesarean (Figure 6A-6B) and post term phase (Figure 7A-7B) (5 mg/kg bw/week), the luminal epithelium was pronounced to be non significant changes to the control group respectively.

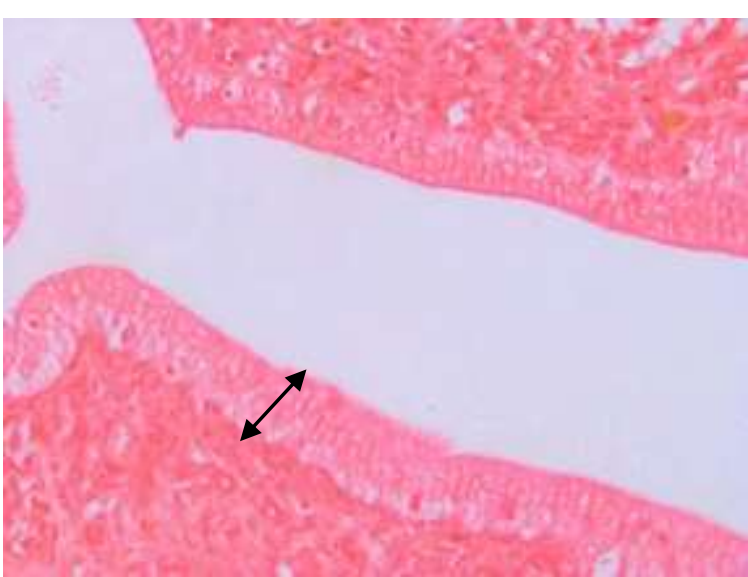

Figure 5a

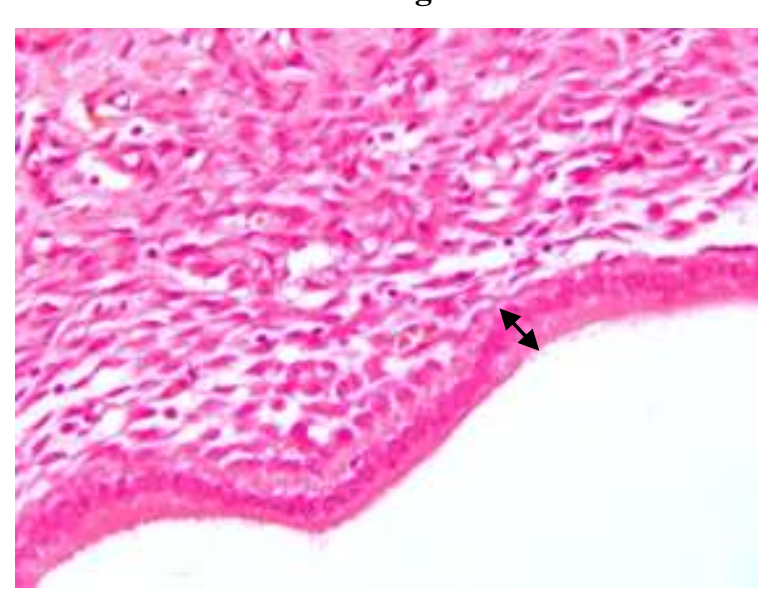

Figure 5c

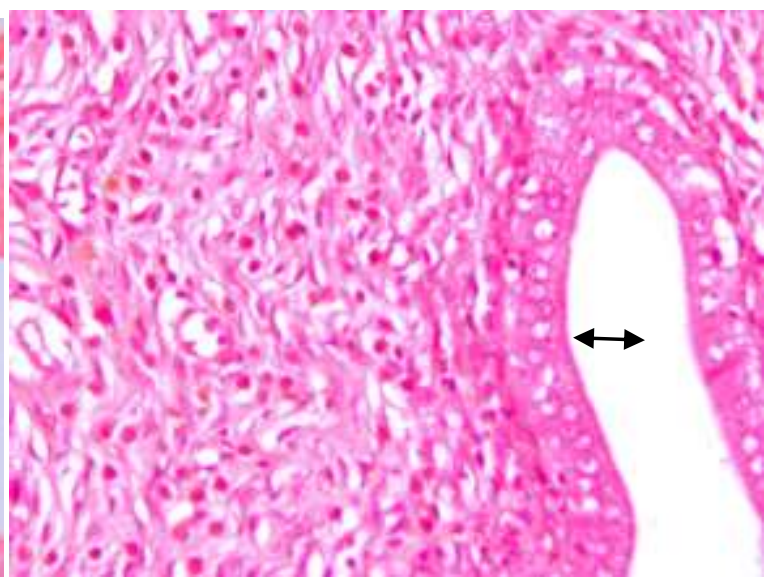

Figure 5b

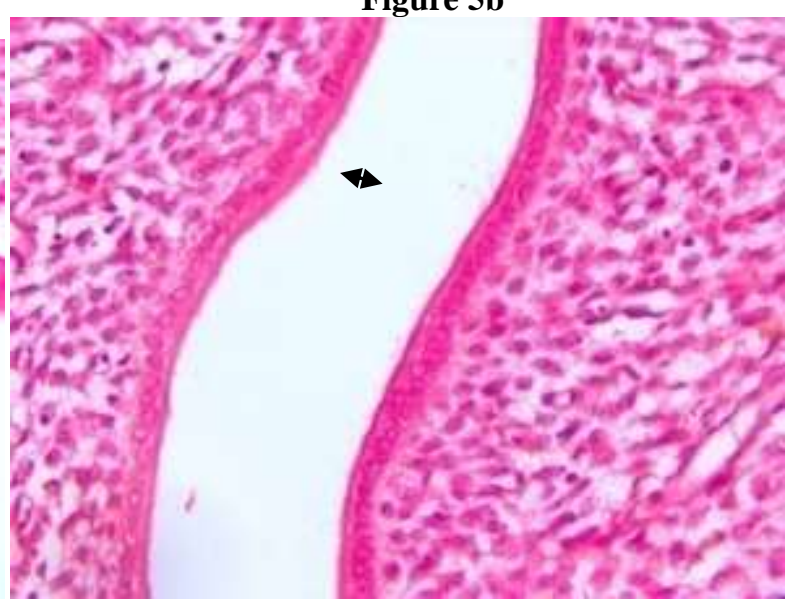

Figure 5d 


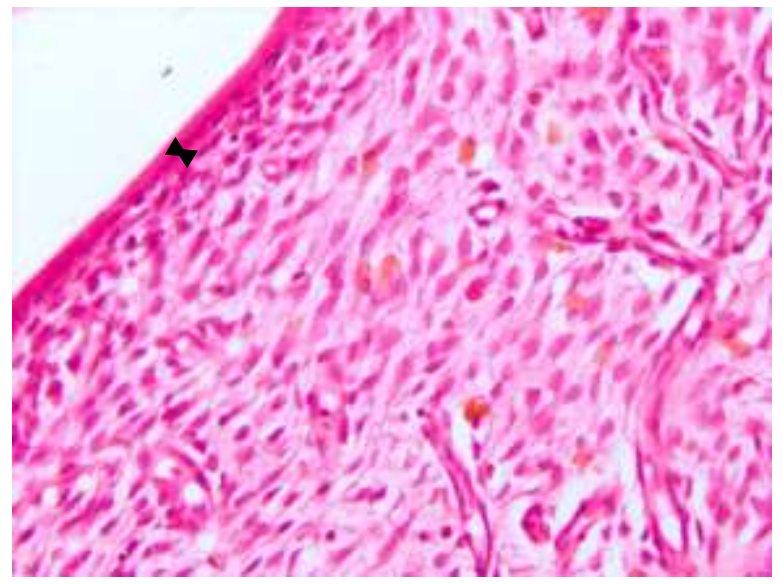

Figure 5e

Figure 5:- The histoarchitecture of uterus of non pregnant phase. A Histology of uterus of group I (control) in animals showed simple and relatively thick columnar epithelium called endothelial lining of the uterine lumen (both sided arrow). B Histology of uterus of BPA treated groups III, IV, V and VI (control) in animals showed decreasing columnar epithelium called endothelial lining of the uterine lumen (both sided arrow). (H\&E, X400).

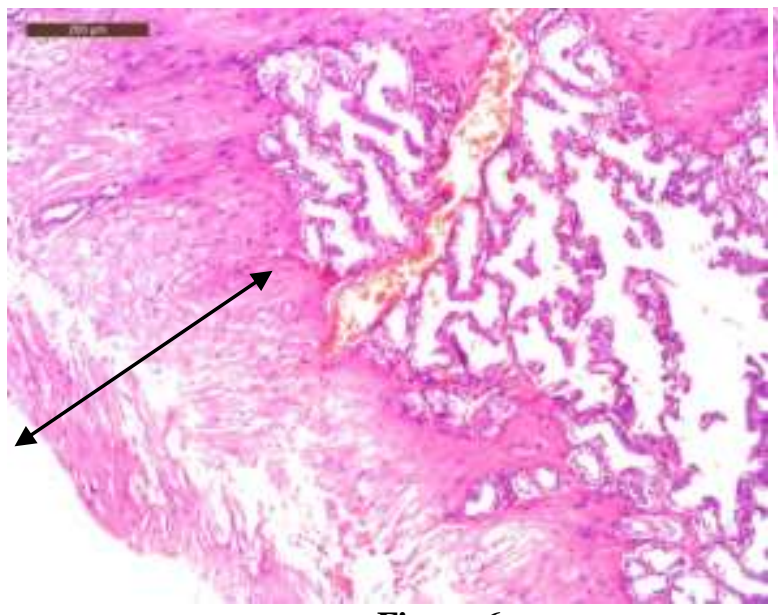

Figure 6a

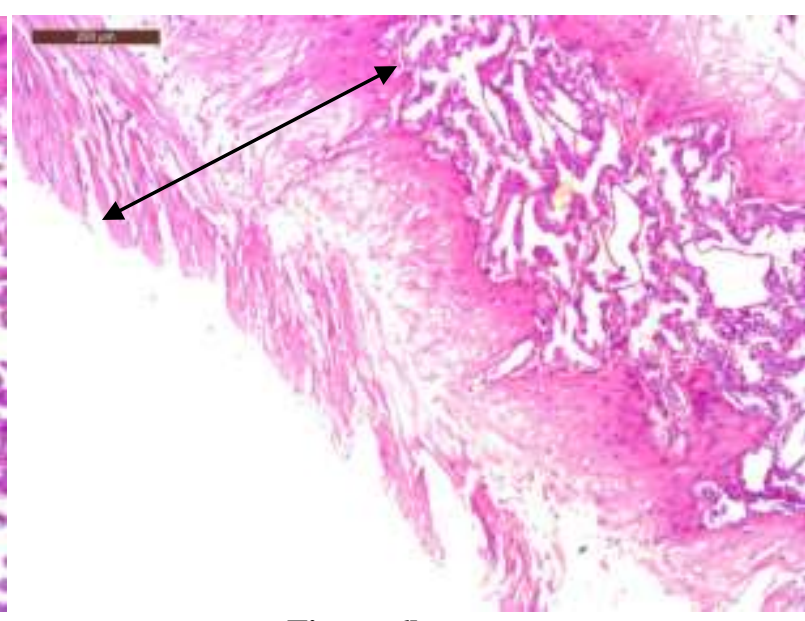

Figure 6b

Figure 6:- The histoarchitecture of uterus of cesarean phase. A-B Histology of group I (control) and group II (5 $\mathrm{mg} / \mathrm{kg}$ bd. wt./week) animals showed thick columnar epithelium called endothelial lining of the uterine lumen (both sided arrow). (H\&E, X400).
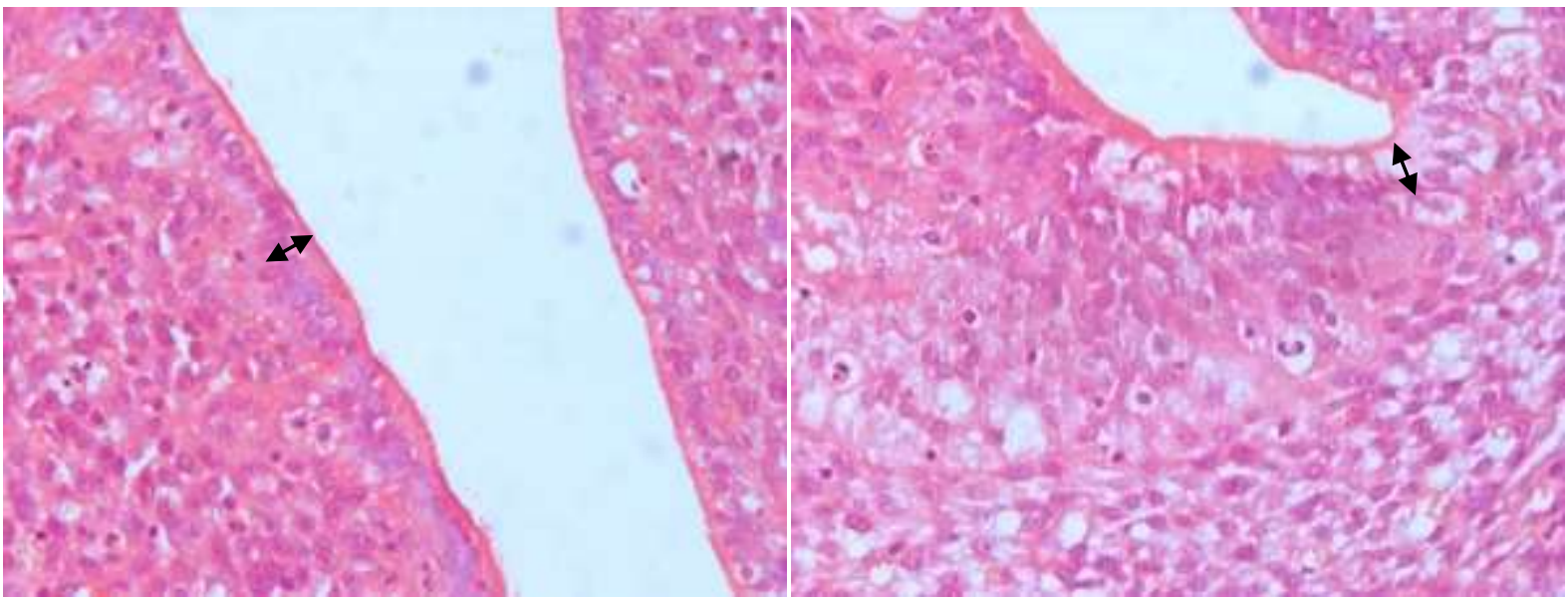


\section{Figure 7a}

Figure 7:- The histoarchitecture of uterus of post term phase. A-B Histology of group I (control) and group II (5 $\mathrm{mg} / \mathrm{kg}$ bd. wt./week) animals showed simple and thick columnar epithelium called endothelial lining of the uterine lumen (both sided arrow). (H\&E, X400).

\section{Discussion:-}

As the present study demonstrates the effects of BPA exposure on female reproductive organs (ovary and uterus) and hormone level (estrogen and progesterone) with the following body weight, several recent studies have also reported such subtle effects in rodents that were exposed to different doses of BPA.

In the present investigation, we noted the significant difference in body weight of BPA-treated female rats during the period of weekly exposure administration by oral gavage in non pregnant phase and non significant difference in cesarean and full term phase. In support to the present findings, Delclos and his colleagues found that BPA doses $\leq$ $2,700 \mu \mathrm{g} / \mathrm{kg}$ bw/day did not affect gestational body weight gain of rat ${ }^{16}$. Moreover, doses of BPA (8, 40, 160 and $800 \mathrm{mg} / \mathrm{kg}$ bw/day) were given orally or subcutaneously to dams, there was no significant difference found in the body weight ${ }^{17}$. Cabaton et al (2011) also reports no statistical difference in the dam weights by treatment groups of BPA exposed perinatally in CD-1 mice ${ }^{18}$. Early prepubertal exposure to BPA (10 and $100 \mathrm{mg} / \mathrm{kg}$ ) in mice significantly decreased body weight from postnatal day 18 to 30 but 0.1 and $1 \mathrm{mg} / \mathrm{kg}$ of BPA treated groups showed no significant differences in body weight ${ }^{19}$ In contrast, a study reported that significant findings were increased body weights of the pups born to BPA-treated females relative to those born to control females in low and high doses of BPA when Sprague-Dawley female rats that were exposed, via their drinking water, to approximately $0.1 \mathrm{mg}$ $\mathrm{BPA} / \mathrm{kg}$ body weight (bw)/day (low dose) or $1.2 \mathrm{mg} \mathrm{BPA} / \mathrm{kg}$ bw/day (high dose) from day 6 of pregnancy through the period of lactation ${ }^{20}$.

Estrogen (estradiol, specifically) and progesterone - that are vital to normal reproductive development and fertility. Both hormones are responsible for the development of follicles. We found that different doses of BPA treated animals have morphological changes in ovaries having atretic follicles because of level of estrogen and progesterone decreased in non pregnant females but normal follicles were seen with normal production of hormone in cesarean and full term females. BPA affected early oogenesis (ESR2) disruption in mouse during prenatal ${ }^{21}$ and decreased ovulation $^{22}$. In one study, low-dose neonatal BPA exposure decreased numbers of all type of follicles and increased atretic follicles in rats during adulthood ${ }^{23}$. In vitro studies on the effects of BPA have locused on mature ovarian follicles. In murine preantral follicles, BPA $(0.003 \mu \mathrm{M})$ extended development to antral follicles ${ }^{24}$. BPA exposure also increased cell proliferation, follicular growth indication, in small antral follicles in neonatally exposed lambs and Wistar rats ${ }^{25,26}$. In a recent study conducted by Lee et al. on adult female rats exposed orally to $1 \mu \mathrm{g} / \mathrm{kg}$ body weight (BW) or $100 \mu \mathrm{g} / \mathrm{kg}$ BW for 90 days, caspase-3 activation was significantly increased by BPA exposure, causing an augmentation of follicular atresia and luteal regression ${ }^{27}$. Follicle activation has been confirmed by Chao et al. (2012), who found that upon BPA exposure, mouse ovaries had significantly decreased primordial follicles but increased primary, secondary and antral follicles ${ }^{28}$. A study conducted on antral follicles isolated from 32-day old mice proved that BPA significantly decreased progesterone and estrogen production ${ }^{29}$. Another study reported that low-dose neonatal BPA exposure increased atretic follicles in rats during adulthood ${ }^{23},{ }^{30}$. The studies suggest that low-dose BPA exposure may alter follicle formation, but high-dose BPA may directly inhibit growth, cause atresia, and induce changes in rodent antral follicles.

In the uterus, estrogens stimulate epithelium proliferation in vivo and play a critical role in uterine epithelial growth, morphogenesis, and secretory activity ${ }^{31}$. The morphological changes in the luminal epithelial of uterus could be observed at high doses of BPA treated animals when compared with control group. The thickness of the total epithelium was significantly reduced after exposure of different doses of BPA (50, 300, 600 and $800 \mathrm{mg} / \mathrm{kg}$ bw/week) when compared with control group whereas at low dose of BPA (5 mg/kg bw/week), the luminal epithelium was pronounced to be non significant changes to the control group. The supportive study reported that treatment with BPA disrupt uterine epithelium. The thickness of the epithelium was significantly reduced after exposure to $50 \mathrm{mg} / \mathrm{kg}$ per day BPA when compared with the control group. The 0.1-mg BPA dose did not cause any difference in the thickness of uterine wall to the control group ${ }^{32}$. In other study, Branham and his collogues stated that the other environmental compounds (DES and EE) induced luminal epithelium hypertrophy and inhibited uterine gland genesis ${ }^{33}$. Further, adult hens that were exposed in ovo on day 4 of incubation to BPA (134 ng/kg) had decreased thickness of their tunica mucosa and density of uterine glandular structures compared with unexposed hens $^{34}$. Other in vivo studies have provided evidence that BPA impairs proliferation in the uterus. In rodents, BPA 
exposure decreased expression of uterine Esrl (estrogen receptor $\alpha$ ), which may lead to inhibit endometrial proliferation in the uterine epithelium and stroma ${ }^{35-38}$. In neonatal exposure to low-dose BPA decreased uterine epithelium proliferation in response to hormone treatments ${ }^{38}$. In two other studies of adult rats, perinatal exposure of BPA caused increase in thickness of uterine epithelia ${ }^{39,40}$. Together, these studies indicate that gestational BPA exposure may be potentially deleterious to uterine morphology in adult females.

\section{Conclusions:-}

BPA affects the reproductive organs (ovary and uterus) and hormone levels of the female rats which increase with the enhancing dose. This study stresses to find the body weight and histology of organs. We found significant difference in body weight and in hormone of non pregnant phase. In continuation with, there is a degeneration of follicles in ovary and reduction in thickness of luminal epithelia of uterus in non pregnant phase. Whereas body weight, hormone level, follicles in ovary and luminal epithelia of uterus in cesarean and post term phase remain unchanged. The present study concludes that the body weight of animals and level of hormones get affected, ovary, and uterus are altered in non pregnant phase whereas in cesarean and post term phase have unaffected organs with unchanged body weight and hormone levels. Thus, exposure of animal and humans to widely prevalent chemical BPA may lead to insidious alteration in reproductive organs.

\section{Acknowledgement:-}

The authors express their sincere gratitude to Head of the Department of Zoology, University of Rajasthan, Jaipur, Rajasthan for providing necessary research facilities for the successful completion of this study.

\section{Conflicts of Interest:-}

The authors declare no conflict of interests.

\section{References:-}

1. Sonnenschein $\mathrm{C}$ and Soto AM: An updated review of environmental estrogen and androgen mimics and antagonists. Journal of Steroid Biochemistry and Molecular Biology 1998; 65:143-150.

2. Vandenberg LN, Maffini MV, Sonnenschein C, Rubin BS and Soto AM: Bisphenol-A and the great divide: a review of controversies in the field of endocrine disruption. Endocrine Reviews 2009; 30:75-95.

3. Le HH, Carlson EM, Chua JP and Belcher SM: Bisphenol A is released from polycarbonate drinking bottles and mimics the neurotoxic actions of estrogen in developing cerebellar neurons. Toxicology Letters 2008; 176:149-156.

4. Vandenberg LN, Hauser R, Marcus M, Olea N and Welshons, WV: Human exposure to bisphenol A (BPA). Reproductive Toxicology 2007; 24(2):139-177.

5. Shuo X, Honglu D, Mary AS, Xiao S and Xiaoqin Y: Preimplantation exposure to bisphenol A (BPA) affects embryo transport, preimplantation embryo development and uterine receptivity in mice. Reproductive Toxicology 2011; 32(4):434-441.

6. Hoekstra EJ and Simoneau C: Release of bisphenol A from polycarbonate: A review. Critical Reviews in Food Science and Nutrition 2013; 53: 386-402.

7. Sekizawa J: Low-dose effects of bisphenol A: a serious threat to human health? Toxicological Sciences 2008; 33:389-403.

8. Witorsch RJ: Endocrine disruptors: can biological effects and environmental risks be predicted? Regulatory Toxicology and Pharmacology 2002; 36:118-130.

9. Fenichel P, Chevalier $\mathrm{N}$ and Brucker-Davis F: Bisphenol A: an endocrine and metabolic disruptor. AnnalesD’Endocrinologie 2013; 74: 211-220.

10. Völkel W, Colnot T, Csanády GA, Filser JG and Dekant W: Metabolism and kinetics of bisphenol A in humans at low doses following oral administration. Chemical Research in Toxicology 2002; 15:1281-1287.

11. Thayer KA, Doerge DR, Hunt D, Schurman SH, Twaddle NC, Churchwell MI, Garantziotis S, Kissling GE, Easterling MR, Bucher JR and Birnbaum LS: Pharmacokinetics of bisphenol A in humans following a single oral administration. Environment International 2015; 83:107.

12. Salian S, Doshi T and Vanage G: Perinatal exposure of rats to Bisphenol- A affects the fertility of male offspring. Life Sciences 2009; 85:742-752.

13. Toyama Y and Yuasa S: Effects of neonatal administration of 17beta-estradiol, beta-estradiol 3 benzoate, or bisphenolA on mouse and rat spermatogenesis. Reproductive Toxicology 2004; 19:181-188.

14. CPCSEA guidelines For Laboratory Animal Facility. 2010; 1-39. 
15. OECD Guideline for Testing Of Chemicals. Acute Oral Toxicity - Fixed Dose Procedure. 420. Adopted $17^{\text {th }}$ Dec 2001.

16. Delclos KB, Camacho L, Lewis SM, Vanlandingham MM, Latendresse JR, Olson GR, Davis KJ, Patton RE, daCosta GG, Woodling KA, Bryant MS, Chidambaram M, Trbojevich R, Juliar BE, Felton RP and Thorn BT: Toxicity evaluation of bisphenol A administered by gavage to Sprague-Dawley rats from gestation day 6 through postnatal day 90. Toxicological Sciences 2014; 139(1):174-97.

17. Yamasaki K, Sawaki M and Takatsuki M: Immature rat uterotrophic assay of Bisphenol A. Environmental Health Perspectives 2000; 108:1147-1150.

18. Cabaton NJ, Wadia PR, Rubin BS, Zalko D, Schaeberle CM, Askenase MH, Gadbois JL, Tharp AP, Whitt GS, Sonnenschein C and Soto AN: Perinatal exposure to environmentally relevant levels of bisphenol A decreases fertility and fecundity in CD-1 mice. Environmental Health Perspectives 2011; 119: 547-552.

19. Nah WH, Park MJ and Gye MC: Effects of prepubertal exposure to bisphenol A on the onset of puberty, ovarian weights, and estrous cycle in female mice. Clinical and Experimental Reproductive Medicine 2011; 38(2): 75-81.

20. Rubin BS, Murray MK, Damassa DA, King JC and Soto AM:Perinatal exposure to low doses of bisphenolA affects body weight, patterns of estrous cyclicity, and plasma LH levels. Environmental Health Perspectives 2001; 109:675-680.

21. Susiarjo M, Hassold T, Freeman E and Hunt P: Bisphenol A exposure in utero disrupts early oogenesis in the mouse. PLoS Genetics 2007; 3:e5.

22. Maffini M, Rubin B, Sonnenschein C and Soto A: Endocrine disruptors and reproductive health: the case of bisphenol-A. Molecular and Cellular Endocrinology 2006; 254:179-186.

23. Li Y, Zhang W, Liu J, Wang W, Li H, Zhu J, Weng S, Xiao S and Wu T: PrepubertalbisphenolA exposure interferes with ovarian follicle development and its relevant gene expression. Reproductive Toxicology 2014; 44:33-40.

24. Trapphoff $\mathrm{T}$, Heiligentag $\mathrm{M}$, El-Hajj $\mathrm{N}$, Haaf $\mathrm{T}$ and Eichenlaub-Ritter $\mathrm{U}$ : Chronic exposure to a low concentration of bisphenol A during follicle culture affects the epigenetic status of germinal vesicles and metaphase II oocytes. Fertility and Sterility 2013; 100(6):1758-1767.

25. Rivera OE, Varayoud J, Rodriguez HA, Munoz-de-Toro M and Luque EH: Neonatal exposure to bisphenol A or diethylstilbestrol alters the ovarian follicular dynamics in the lamb. Reproductive Toxicology 2011;32:304312.

26. Rodríguez HA, Santambrosio N, Santamaría CG, Muñoz-de-Toro M and Luque EH: Neonatal exposure to bisphenol A reduces the pool of primordial follicles in the rat ovary. Reproductive Toxicology 2010, 30:550557.

27. Lee SG, Kim JY, Chung JY, Kim YJ, Park JE, Oh S, Yoon YD, Yoo KS, Yoo YH and Kim JM: Bisphenol A exposure during adulthood causes augmentation of follicular atresia and luteal regression by decreasing $17 \beta$ estradiol synthesis via downregulation of aromatase in rat ovary. Environmental Health Perspectives 2013; 121:663-669.

28. Chao HH, Zhang XF, Chen B, Pan B, Zhang LJ, Li L, Sun XF, Shi QH and Shen W: Bisphenol A exposure modifies methylation of imprinted genes in mouse oocytes via the estrogen receptor signaling pathway. Histochemistry and Cell Biology 2012; 137:249-259.

29. Peretz J, Gupta RK, Singh J, Hernandez-Ochoa I and Flaws JA: Bisphenol A impairs follicle growth, inhibits steroidogenesis, and downregulates rate limiting enzymes in the estradiol biosynthesis pathway. Toxicological Sciences 2011; 119:209-217.

30. Gamez JM, Penalba R, Cardoso N, Bernasconi PS, Carbone S, Ponzo O, et al. Exposure to a low dose of bisphenol A impairs pituitary-ovarian axis in prepubertal rats: effects on early folliculogenesis. Environ ToxicolPharmacol2015;39:9-15.

31. Gray CA, Bartol FF, Tarleton BJ, Wiley AA, Johnson GA, Bazer FW and Spencer TE: Developmental biology of uterine glands. Biology of Reproduction 2001; 65:1311-1323.

32. Schonfelder G, Friedrich K, Paul M and Chahoud I: Developmental effects of prenatal exposure to bisphenol A on the uterus of rat offspring. Neoplasia 2004; 6:584-594.

33. Branham WS, Zehr DR, Chen JJ and Sheehan DM: Uterine abnormalities in rats exposed neonatally to diethylstilbestrol, ethynylestradiol, or clomiphene citrate. Toxicology 1988; 51:201-212.

34. Yigit F and Daglioglu S: Histological changes in the uterus of the hens after embryonic exposure to bisphenol A and diethylstilbestrol. Protoplasma2010; 247: 57-63. 
35. Berger RG, Foster WG and DeCatanzaro D: Bisphenol-A exposure during the period of blastocyst implantation alters uterine morphology and perturbs measures of estrogen and progesterone receptor expression in mice. Reproductive Toxicology 2010; 30:393-400.

36. Bosquiazzo VL, Varayoud J, Munoz-de-Toro M, Luque EH and Ramos JG: Effects of neonatal exposure to bisphenolA on steroid regulation of vascular endothelial growth factor expression and endothelial cell proliferation in the adult rat uterus. Biology of Reproduction 2010; 82:86-95.

37. Bromer JG, Zhou Y, Taylor MB, Doherty L and Taylor HS: Bisphenol-A exposure in utero leads to epigenetic alterations in the developmental programming of uterine estrogen response. FASEB J, 2010; 24:2273-2280.

38. Varayoud J, Ramos JG, Bosquiazzo VL, Munoz-de-Toro M and Luque EH: Developmental exposure to bisphenol A impairs the uterine response to ovarian steroids in the adult. Endocrinology 2008; 149:5848-5860.

39. Mendoza-Rodríguez CA, García-Guzmán M, Baranda-Avila N, Morimoto S, Perrot-Applanat M and Cerbón M: Administration of bisphenol A to dams during perinatal period modifies molecular and morphological reproductive parameters of the offspring. Reproductive Toxicology 2011; 31:177-183.

40. Vigezzi L, Bosquiazzo VL, Kass L, Ramos JG, Munoz-de-Toro M and Luque EH: Developmental exposure to bisphenol A alters the differentiation and functional response of the adult rat uterus to estrogen treatment. Reproductive Toxicology 2015;52:83-92. 